\title{
DNA Modified with Metal Nanoparticles: Preparation and Characterization of Ordered Metal-DNA Nanostructures in a Solution and on a Substrate
}

\author{
Nina Kasyanenko, ${ }^{1}$ Mikhail Varshavskii, ${ }^{1}$ Eugenii Ikonnikov, ${ }^{1}$ \\ Evgenii Tolstyko, ${ }^{1}$ Roman Belykh, ${ }^{1}$ Petr Sokolov, ${ }^{1}$ Vladimir Bakulev, ${ }^{1}$ \\ Valery Rolich, ${ }^{1}$ and Konstantin Lopatko ${ }^{2}$ \\ ${ }^{1}$ Faculty of Physics, Saint Petersburg State University, Universitetskaya Nab. 7/9, Saint Petersburg 199034, Russia \\ ${ }^{2}$ National University of Life and Environmental Sciences of Ukraine, Heroes Defense Street 15, Kyiv 03041, Ukraine \\ Correspondence should be addressed to Nina Kasyanenko; n.kasyanenko@spbu.ru
}

Received 25 September 2015; Revised 27 November 2015; Accepted 29 November 2015

Academic Editor: William Yu

Copyright ( 2016 Nina Kasyanenko et al. This is an open access article distributed under the Creative Commons Attribution License, which permits unrestricted use, distribution, and reproduction in any medium, provided the original work is properly cited.

DNA interaction with silver and aluminum nanoparticles in a solution has been investigated with the AFM, SEM, dynamic light scattering, viscometry, and spectral methods. The comparison of DNA interaction with nanoparticles synthesized by the reduction of $\mathrm{Ag}^{+}$ions and with nanoparticles obtained by the electric discharge plasma method was done. DNA metallization in a solution and on $n$-silicon surface with metal nanoparticles or by the reduction of silver ions after their binding to DNA was executed and studied. It was shown that DNA strands with regular location of silver or aluminum nanoparticles can be prepared. The conditions for the formation of silver nanoparticles and silver nanoclusters on DNA were analyzed.

\section{Introduction}

The usage of biopolymers for the creation of different nanostructures is now a widely applied technique. At present DNA nanostructures in many cases are formed with the DNA origami technology $[1,2]$ due to the high specific interactions between complementary bases. An alternative method employs nonspecific interactions in DNA solution for the construction of nanosystems. The manipulations with solvent quality via the change in temperature or in solvent composition, $\mathrm{pH}$ and ionic strength variation, utilization of ligand binding, and organization of supramolecular structures in a solution can be extended to the manufacturing of DNA nanostructures. DNA is a unique polymer with extremely high charge density and huge bending stiffness. The relatively stable and tough double helix structure, however, can easily be transformed into a flexible single-stranded conformation. This allows us to use the conformational transitions for the formation of multicomponent systems and nanostructures. The specific binding of different ligands with a macromolecule provides the targeted modification of the polymer chain. One of the amazing challenges is to create nanowires and waveguides by the metallization of DNA molecules [3-5]. Two alternative approaches can be used for DNA metallization in a solution and on a substrate: the DNA linking with metallic nanoparticles and the reduction of silver ions after their binding to DNA.

In our research the DNA connection with metallic nanoparticles in a solution is considered. The optimization of such an approach can provide its further usage in the construction of multicomponent systems with amazing properties for nanoelectronics, nanooptics, and nanophotonics. Indeed, nanoparticles of noble metals have unique plasmonic properties and different applications $[3,6,7]$. Metal nanoparticles (NPs) play an important role in biomedical applications; for example, they can be employed in biosensor devices, for the diagnostics and treatment of various pathologies. The synthesis of multifunctional plasmonic structures that combine the attractive plasmonic properties of nanoparticles with other functionalities such as photoluminescence is of 
great interest. Through rational design and engineering, "smart" multifunctional nanomaterials can be used in nanomedicine.

In contrast to nanoparticles, the smallest luminescence metal nanoclusters without plasmonic resonance can also be used for the bioimaging and other applications [8-13]. The noble metal quantum clusters (NMQCs) have intriguing photophysical and chemical properties. They have luminescence in the visible region of spectrum. The synthesis of NMQCs on macromolecules in the liquid phase produces polymers with amazing properties for numerous optical and bioimaging applications. The use of DNA as template for the creation of such systems can provide possibilities for new applications. It can give a way, for example, to detect the specific sequences on DNA. The dsDNA has only few positions for NMQCs arising in contrast to ssDNA with numerous sites for the binding of cations. New results for NMQCs synthesis on the doublestranded DNA raise new questions about the localization of clusters and DNA conformation.

From the discussed above it follows that DNA metallization is a promising approach for the creation of perspective systems for new technologies. Indeed, the metal nanoparticle plasmonics is a rapidly developed technique. Plasmon effects in nanocomposite materials lead to a strong local field enhancement of incident electromagnetic wave influence on a sample. The incorporation of nanoparticles into polymer systems can be used for engineering of structures with desired optical properties. The incorporation of colloidal nanoparticles into macroscopic aggregates using DNA as linking element was performed in [14]. This strategy allows one to control the distance between particles and their properties in the targeted macroscopic structure. Using double-stranded DNA we can prepare structures with modified properties. For example, we can create the polyplexes (DNA-polymer complexes) with NPs via self-assembling in a solution.

In our research we use high molecular double-stranded DNA for the formation structures with metal nanoparticles or nanoclusters. This approach can turn the application of these systems from biological area to nanoelectronics, nanophotonics, and new material production.

\section{Materials and Methods}

2.1. Materials. Calf thymus DNA with the molecular mass $M=8 \times 10^{6}$ determined from DNA intrinsic viscosity in $0.15 \mathrm{M} \mathrm{NaCl}$ was used. DNA and other chemicals $\left(\mathrm{AgNO}_{3}\right.$, $\mathrm{NaBH}_{4}$, and $\mathrm{MgCl}_{2}$ ) were acquired in the Sigma company.

Silver (Ag-NPs-1) and aluminum (Al-NPs) nanoparticles were obtained with the electric discharge plasma method [15]. Silver nanoparticles were also synthesized in a water solution by the reduction of $\mathrm{Ag}^{+}$ions, usually at $\mathrm{AgNO}_{3}$ concentration $8 \times 10^{-5} \mathrm{M}$ with $10^{-4} \mathrm{M} \mathrm{NaBH}_{4}$ (Ag-NPs-2), or were obtained according to the procedure described in [16] (Ag-NPs-3).

2.2. Viscometry. The relative viscosity of DNA solutions $\eta_{r}=\eta / \eta_{0}$, where $\eta$ and $\eta_{0}$ are the solution and solvent viscosities, was used to calculate the reduced viscosity $\eta_{\text {red }}=$ $\left(\eta_{r}-1\right) / C$, where $C$ is the DNA concentration. The $\eta_{\text {red }}$ value extrapolated to zero concentration gives the intrinsic viscosity of DNA $[\eta]$ which depends on the molecular mass $M$, chain rigidity (Kuhn segment length $A$ ), hydrodynamic length of DNA molecule $L$, and linear swelling coefficient $\alpha$ ( $\Phi$ is the Flory coefficient):

$$
[\eta]=\Phi \frac{(L A)^{3 / 2}}{M} \alpha^{3}
$$

2.3. Dynamic Light Scattering (DLS). Experiments were carried out using the "PhotoCor Complex" (Photocor Instruments, Inc., Moscow, Russia) apparatus. It comprised a digital correlator (288 channels, $10 \mathrm{~ns}$ ), standard goniometer (10$150^{\circ}$ ), and a thermostat with the temperature stabilization of $0.05^{\circ} \mathrm{C}$. A single mode solid-state linear polarized laser (wavelength $\lambda=654 \mathrm{~nm}$ ) was used as an excitation source. The normalized intensity homodyne autocorrelation functions were fitted by the ILT regularization procedure incorporated in the "DynaLS" software providing the relaxation time and the hydrodynamic radius distributions.

2.4. Spectral Methods. Circular dichroism spectra of DNA were registered with the Mark IV autodichrograph (Jobin Ivon). Absorption spectra were recorded with a SF-56 spectrophotometer (Russia). Luminescence spectra were obtained with a Hitachi-850 using a $1 \mathrm{~cm}$ quartz cuvette. The luminescence excitation and emission spectra were corrected for the spectral sensitivity of the instrument.

2.5. Scanning Microscopy. Atomic Force Microscopy (AFM) images were obtained with the tapping mode and the direct scanning methods with NanoScope $4 \mathrm{a}$ (Veeco) and Ntegra Spectra NT-MDT (Russia) devices. Samples were prepared by DNA fixation on mica surface with $\mathrm{MgCl}_{2}$ addition into a solution. The drop of solution was placed on the surface of mica followed by washing the sample with distilled water and drying under vacuum. We use also $n$-silicon substrates without modification after etching with hydrofluoric acid. It should be noted that if the drop of solution was only dried (the sample was not washed) the images show the formation of aggregates. Therefore, we waited for 10 minutes after applying a drop of solution onto the silicon surface. After that the substrate was washed with distilled water and dried.

The scanning electron microscopes (SEM) Zeiss Merlin, Zeiss SUPRA 40VPSEM, and scanning ion helium microscope (Zeiss ORION) of the Saint Petersburg State University Resource Center "Nanotechnology" were used.

\section{Results and Discussion}

Silver nanoparticles Ag-NPs-1 and Ag-NPs-2 have similar plasmon resonance peaks (Figure 1). They show good stability in aqueous solutions. The spectral properties of Ag-NPs-1 were examined during 3 months. They have not shown any visible changes. The hydrodynamic radius $R_{H}$ of nanoparticles was obtained from DLS data. The translation diffusion coefficient $D_{t}$ was calculated from the slope of the linear 


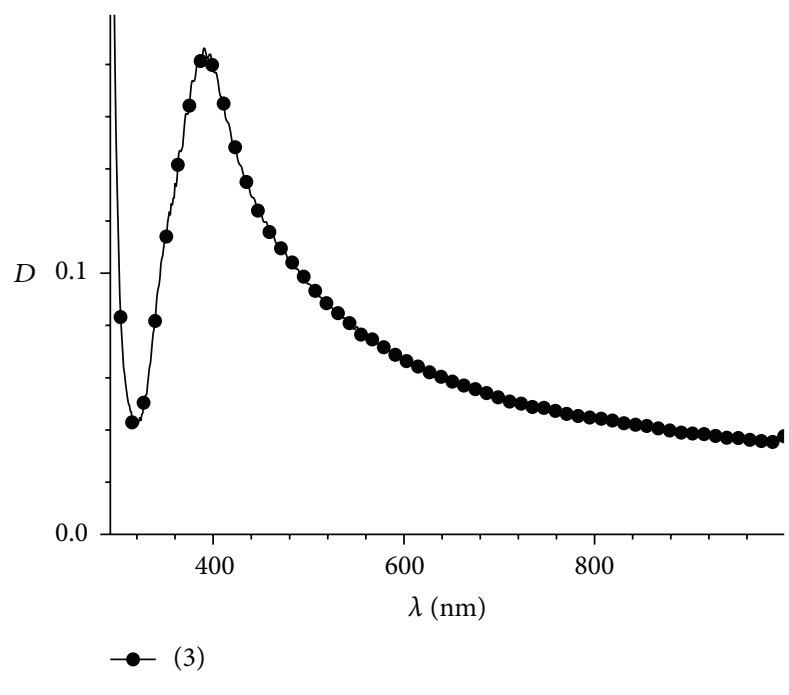

(a)

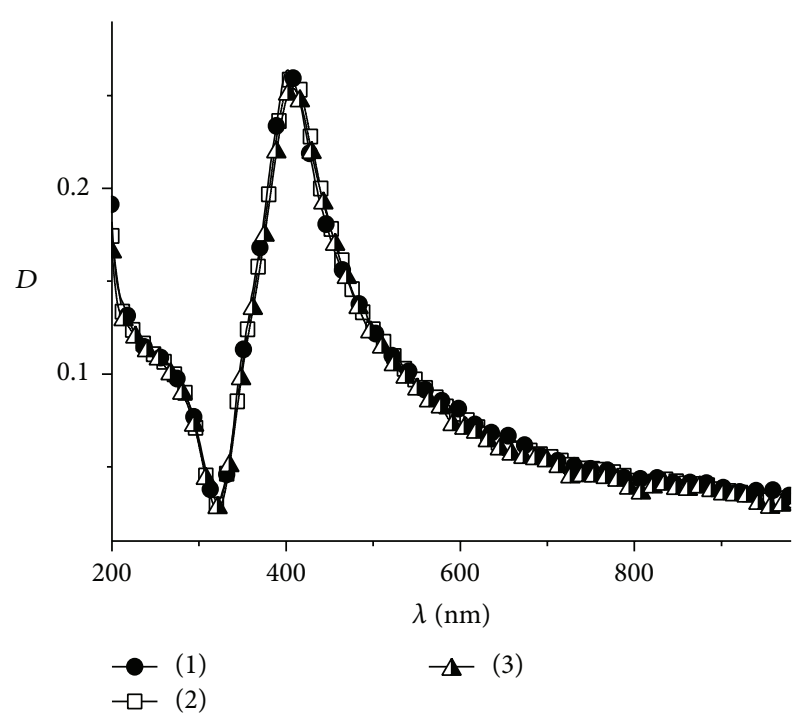

(b)

Figure 1: Plasmon resonance peak (PRP) for Ag-NPs-1 (a) and Ag-NPs-2 (b) registered just after preparation (1), in 1 day (2) and in 2 weeks (3).

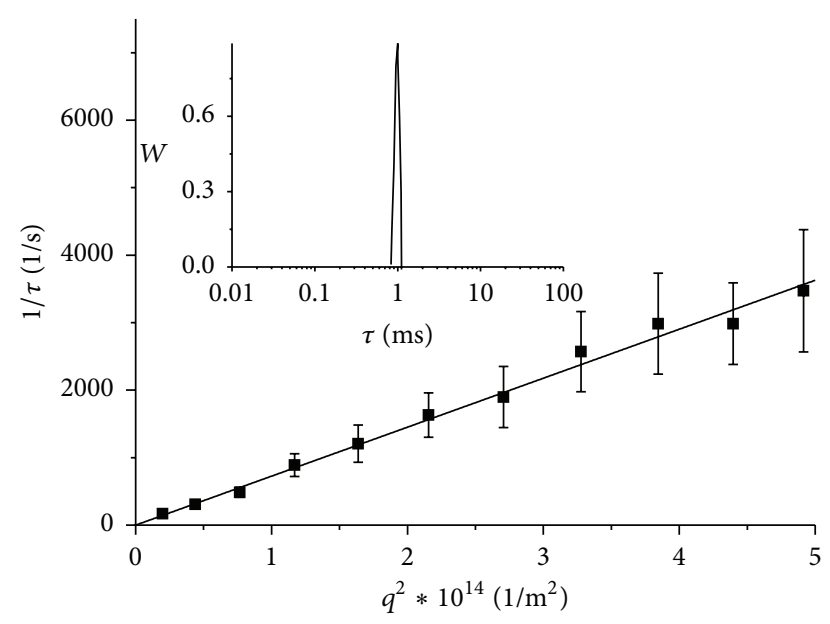

FIGURE 2: The dependence of the relaxation rate $1 / \tau$ on $q^{2}$. Insert shows the time relaxation distribution for Ag-NPs-2.

dependence of the relaxation rate $1 / \tau$ ( $\tau$ is the relaxation time) versus $q^{2}$ ( $q$ is the scattering vector), Figure 2 .

The narrow unimodal time relaxation distribution was observed for Ag-NPs-1 (Figure 2, insert). The hydrodynamic radius value $R_{H}=(33 \pm 2) \mathrm{nm}$ for Ag-NPs- 2 was determined from $D_{t}$ according to the formula $D_{t}=k T /\left(6 \pi \eta_{0} R_{H}\right)$. The Ag-NPs-2 show the bimodal time relaxation distribution. The dominant mode gives $R_{H}=(35 \pm 1) \mathrm{nm}$. The presence of a small number of particles with $R_{H}=(4 \pm 1) \mathrm{nm}$ follows from the relatively small fast mode.

The AFM images of Ag-NPs-1 and Ag-NPs-2 on the mica surface are presented in Figure 3. The size (diameter) of AgNPs-1 is about $30 \mathrm{~nm}$ (see the images of nanoparticles with their processing in Figures 3(a) and 3(b)). The image of AgNPs-2 (Figure 3(c)) gives approximately the same size of particles. One can see also the small particles with the size of about $5 \mathrm{~nm}$. The analysis of Figure 3(c) gives the average particles diameter and height $h=(16 \pm 10) \mathrm{nm}$ (Figure 3(d)).

It was shown that Ag-NPs-1 and Ag-NPs-2 do not interact with the DNA molecule in a solution. Indeed, neither DNA absorption spectrum nor plasmon resonance peak is changed after the mixing of DNA and NPs in a solution (Figure 4(a)). Note that the high concentration of nanoparticles induces the light scattering in a solution, so the CD spectra for nonmolecular systems cannot reflect the real optical activity of DNA. Nevertheless, at small amount of NPs in a solution the DNA CD spectrum is practically unchanged (Figure 4(b)). The volume of DNA molecule also does not change with the addition of Ag-NPs-1 and Ag-NPs-2 into the solution (Figure 4(c)).

The AFM images of DNA with NPs on mica surface fixed with $\mathrm{Mg}^{2+}$ ions are presented in Figure 5.

When we use the solutions of dsDNA (double-stranded DNA) in $5 \mathrm{mM} \mathrm{NaNO} 3$ with Ag-NPs-1 or Ag-NPs-2 the nanoparticles and DNA are located on the mica surface separately from each other, except for a few contacts (Figure 5). The shape of Ag-NPs-1 and Ag-NPs-2 is close to spherical. After the thermal denaturation of DNA one can see the emergence of DNA-Ag-NPs contacts. At high temperatures the DNA molecule becomes more flexible and hydrophobic bases open to contact with water. We suppose that DNA denaturation facilitates the DNA binding with silver nanoparticles.

Another type of silver nanoparticles, Ag-NPs-3, was prepared in a solution according to [16]. Ag-NPs-3 have different shapes and their colloids have different colors (Figure 6). DLS data for Ag-NPs-3 indicate the presence of the main fraction 


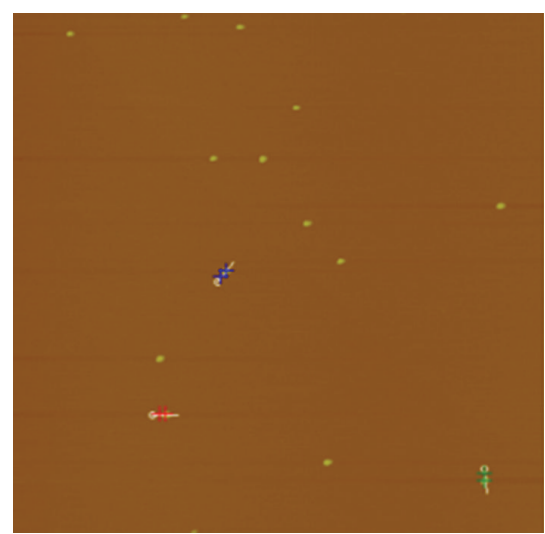

(a)

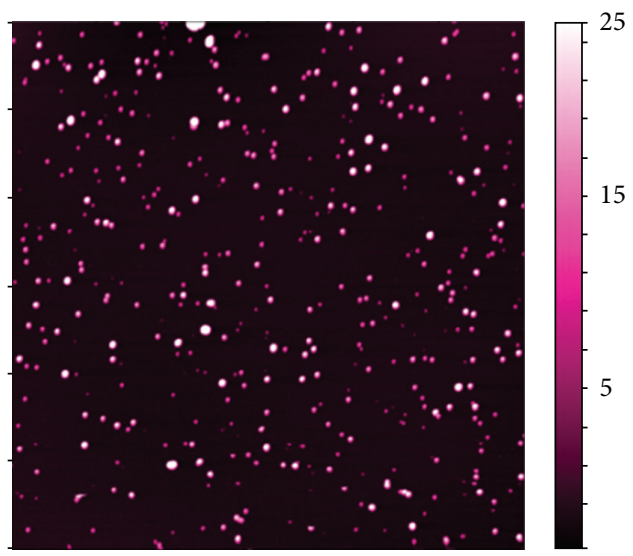

(c)
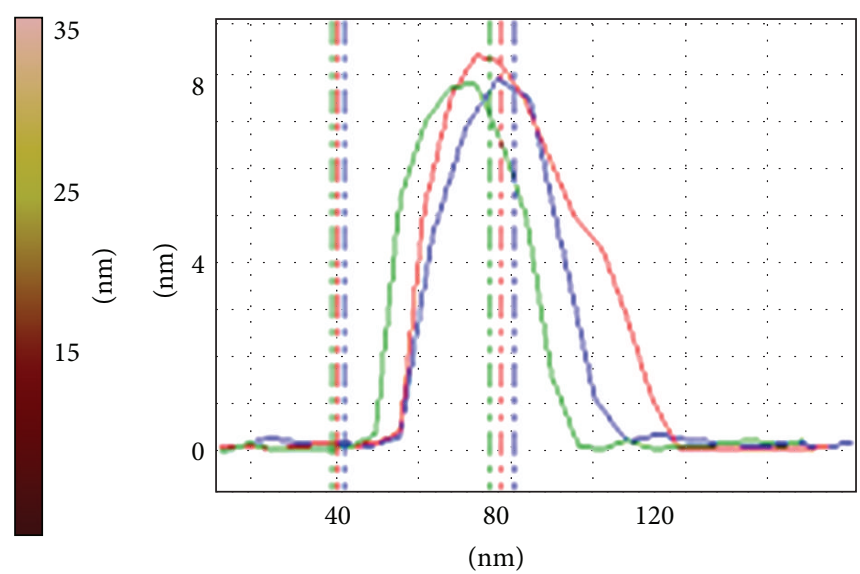

(b)

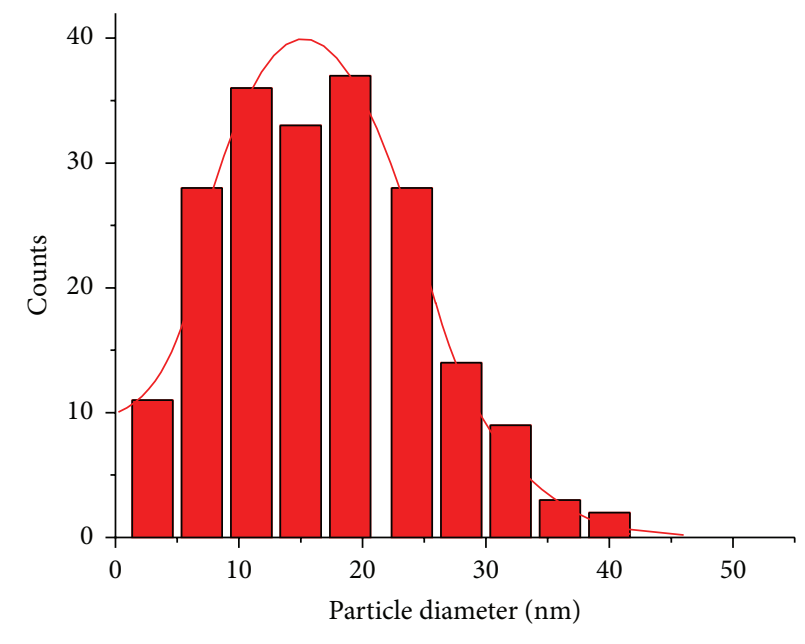

- High from AFM $(16 \pm 10) \mathrm{nm}$

(d)

FigURE 3: AFM images $(3 \mu \mathrm{m} \times 3 \mu \mathrm{m})$ for Ag-NPs-1 on mica obtained with NanoScope $4 \mathrm{a}$, tapping mode (a) with the processing of image (b), and AFM image of Ag-NPs-2 on mica obtained with Ntegra Spectra (direct scanning) (c) with the size and height distribution for particles (d).

TABLE 1: DLS data for colloidal solutions with Ag-NPs-3.

\begin{tabular}{lccc}
\hline Solution color & $R_{H}(\mathrm{~nm})$ & AspRatio (oblate) & AspRatio (prolate) \\
\hline Blue & $15.3 \pm 0.1$ & 2 & \\
Pink & $20.8 \pm 0.2$ & 3.2 & \\
Violet & $24.3 \pm 0.1$ & 1.8 & \\
Red & $26.0 \pm 0.3$ & & 0.40 \\
Yellow & $23.4 \pm 0.1$ & & 1 \\
\hline
\end{tabular}

AspRatio is the relation of axis for the equivalent ellipsoid from the rotational diffusion coefficient.

of NPs (Table 1) and the minor fraction of the smallest nanoparticles observed in DLS and SEM experiments.

The addition of DNA into colloids with different silver nanoparticles (Ag-NPs-3) does not cause a significant transformation of the plasmon peak, but DNA stabilizes the colloid. The examination of DNA conformation after the addition of Ag-NPs-3 shows the destruction of DNA doublestranded structure due to the high $\mathrm{pH}$ value in a colloid according to the selected procedure of the NPs synthesis. The interaction of Ag-NPs-3 with DNA causes in this case the organization of DNA associates with silver nanoparticles, as seen in SEM images (Figure 7). It should be noted that hydrophobic silicon can induce the formation of associates on the substrate.

All the results described above were obtained after mixing the DNA and NPs solutions. It was shown that silver nanoparticles do not interact with dsDNA in a solution. The destruction of the DNA secondary structure (by heating or by changing $\mathrm{pH}$ ) allows them to interact.

The preliminary DNA fixation on the substrate may lead to other results. Indeed, the location of DNA on a silicon surface followed by the addition of a small drop of colloid with Ag-NPs-1 causes the attraction of NPs to the area on silicon with fixed DNA (Figure 8) in contrast to the lack of interaction in the solution for the same components 


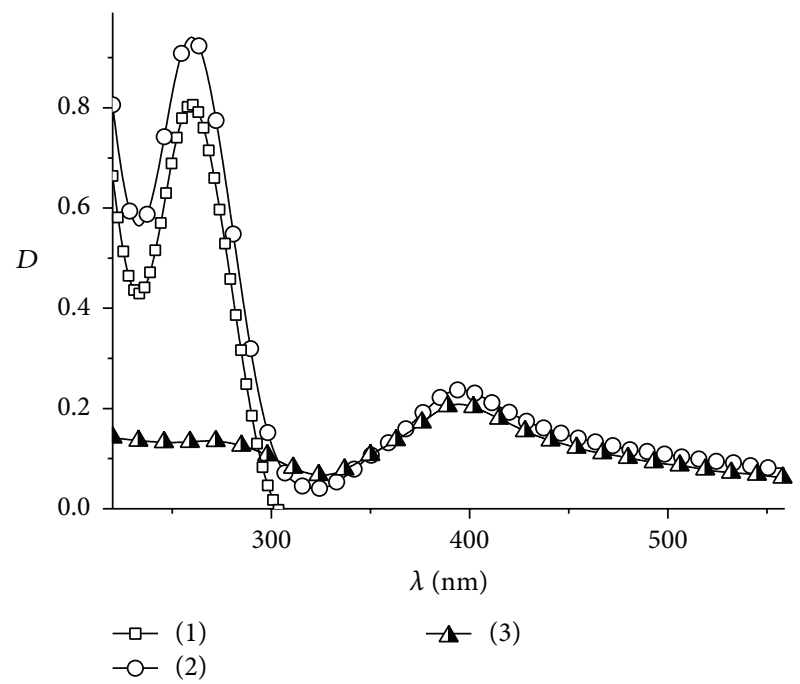

(a)

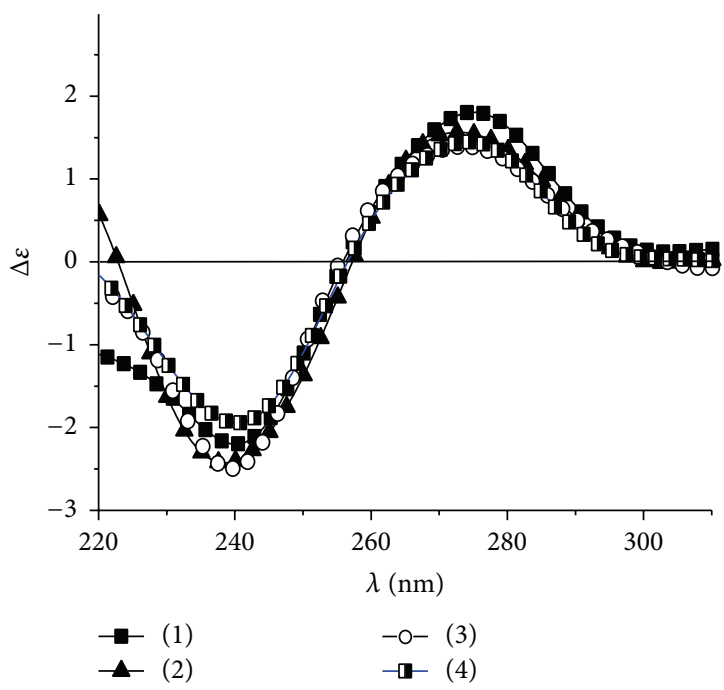

(b)

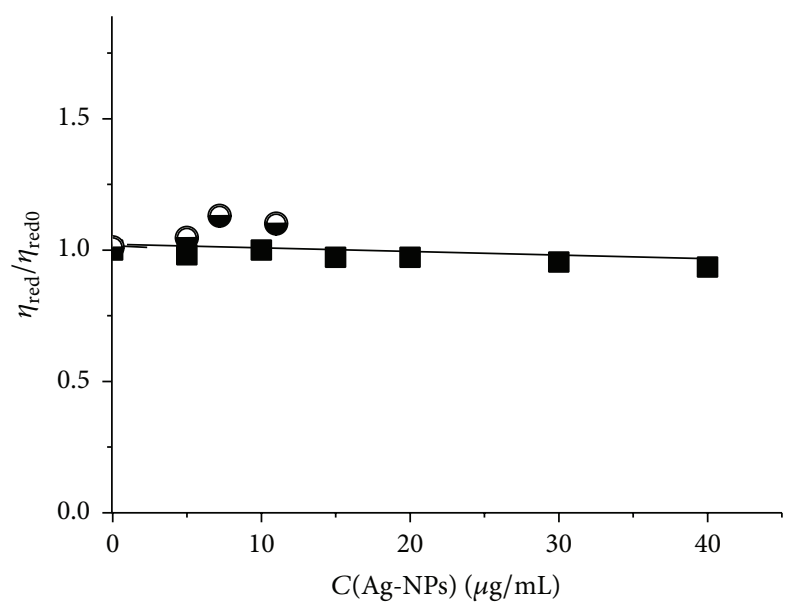

Ag-NPs-2

Ag-NPs-1

(c)

Figure 4: Optical density of solutions (a): DNA in $5 \mathrm{mMNaNO}_{3}$ (1), DNA with Ag-NPs-2 (2) and Ag-NPs-2 (3), and C(Ag-NPs-2) = $25 \mu \mathrm{g} / \mathrm{mL}$; $\mathrm{CD}$ spectra (b) of DNA in $5 \mathrm{mM} \mathrm{NaNO}_{3}$ (1), DNA with Ag-NPs-2 (2-4), and C(Ag-NPs-2) = 7.5 (2), 10 (3), and 15 (4) $\mu$ g/mL; the dependence of the relative change in the reduced viscosity of DNA solutions (c) on concentrations of Ag-NPs-1 (1) and Ag-NPs-2 (2), $\eta_{\text {redo }}$-reduced viscosity of DNA solution without Ag-NPs-2. C (DNA $)=0.005 \%$.

(see Figure 5). DNA molecules were fixed on the $n$-silicon surface according to the procedure described in [5]. As a result, nanoparticles completely cover the DNA strands on the $n$-silicon surface (Figure 8). Actually, as it has been shown previously, the DNA fixation alters the electrical properties of $n$-silicon $[17,18]$. We believe that this is exactly the substrate that provides the fixation of Ag-NPs-1 on DNA. As an additional control method of metallization of DNA on silicon surface we use a scanning ion helium microscope (SIM). The pictures were made during the registration of secondary electrons in the microscope (SIM). The pictures were made during the registration of secondary electrons in the scanning beam of helium ions $(33 \mathrm{keV})$. The small ion beam current (less than $1 \mathrm{pA}$ ) has no significant negative impact on the object under study.

In this way we can suppose only a very weak binding of silver NPs with double-stranded DNA (dsDNA) in a solution and a much more significant binding of silver nanoparticles with DNA fixed on the substrate due to the $n$ silicon influence. Indeed, the AFM images of dsDNA fixed on the silicon surface from the solution with Ag-NPs-1 and Ag-NPs-2 show only few NPs on DNA chains (Figure 5), in spite of the fact that the destabilization of the DNA secondary structure by heating or due to the change in $\mathrm{pH}$ leads to a quite significant binding of nanoparticles to ssDNA (Figures 5 and 7). 


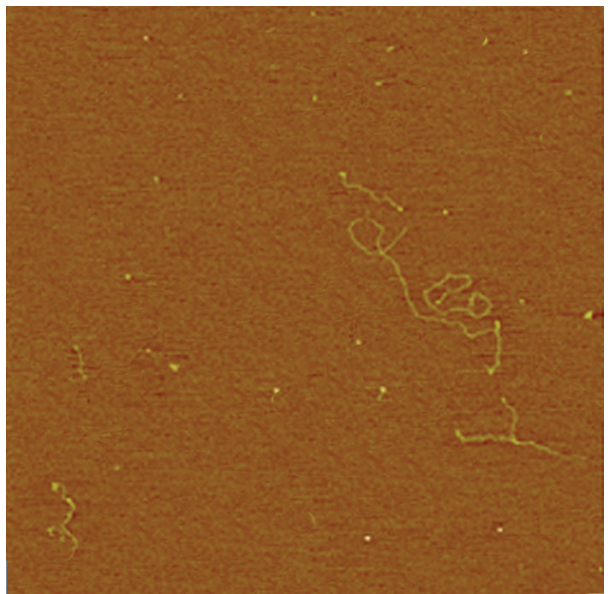

(a)

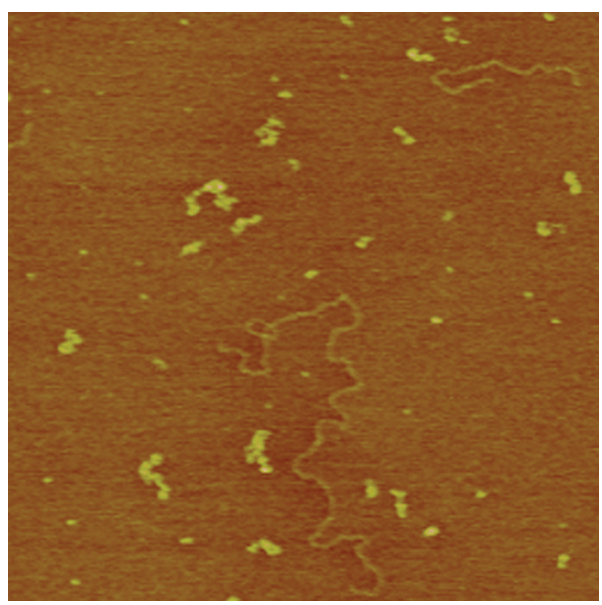

(c)

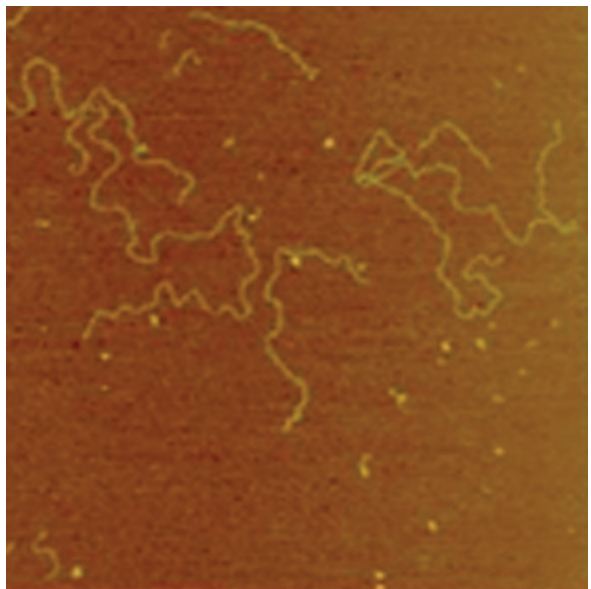

(b)

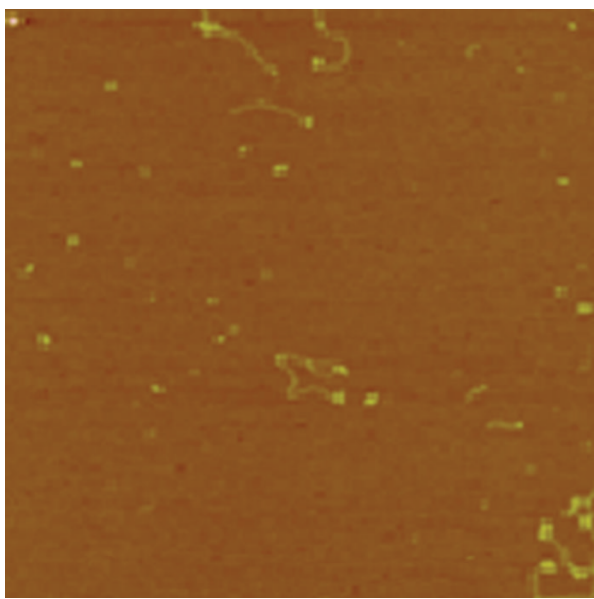

(d)

Figure 5: AFM images of DNA with Ag-NPs-1 (a) and Ag-NPs-2 (b) fixed on mica from solution at $21^{\circ} \mathrm{C}$; DNA with Ag-NPs-1 after the mixing of components at $80^{\circ} \mathrm{C}(\mathrm{c})$ and $100^{\circ} \mathrm{C}$ (d). NanoScope $4 \mathrm{a}$ (tapping mode) was used. The size of the images is $3 \mu \mathrm{m} \times 3 \mu \mathrm{m}(\mathrm{a}, \mathrm{c})$ and $2 \mu \mathrm{m} \times 2 \mu \mathrm{m}(\mathrm{b}, \mathrm{d})$.

It was shown earlier [5] that the addition of a drop of solution with reducing agent on the surface with fixed DNA- $\mathrm{Ag}^{+}$complexes induces the formation of DNA-silver nanowires, and the silicon provides additional electrons for the reduction of silver ions. The specific way of DNA fixation, the selection of silver ions, and reductant concentrations can lead to the fabrication of ordered DNA fibers on silicon with the regular arrangement of silver nanoparticles on DNA strands (Figure 9).

It is interesting to compare the behavior of silver and aluminum nanoparticles in DNA solutions. The Al-NPs in water were in a partially oxidized state and show a rather good stability. For AFM measurements the mica were modified with APS according to the procedure described in [19]. The Al-NPs in a solution consist of spherical particles with the diameter varying from 10 to $150 \mathrm{~nm}$ and rod-like structures with a typical width of $3-5 \mathrm{~nm}$ and the length of $200 \mathrm{~nm}$ (Figures 10(a) and 10(b)).
Size distribution for Al-NPs (DLS data) has two modes which give two $R_{H}$ values: $(41 \pm 2) \mathrm{nm}$ and $(110 \pm 4) \mathrm{nm}$ (Figures 10(c) and 10(d)).

It was observed that the spectral properties of DNA are practically unchanged after adding the Al-NPs (Figure 11). The partial precipitation was observed after the centrifugation of the resulting colloid for $15 \mathrm{~min}$ at $18000 \mathrm{rot} / \mathrm{min}$. As a result, the examination of the bottom fraction in a solution without sediment with the SEM technique shows a net of DNA molecules on $n$-silicon surface with small metal NPs of the same size located exclusively on DNA strands (Figure 12).

We can conclude that DNA separates and binds only small spherical Al-NPs from the polydisperse system. The rodlike and large spherical particles do not produce the regular sites of binding on DNA. We can see big aggregates of DNA molecules containing different Al-NPs on the silicon surface as well. 


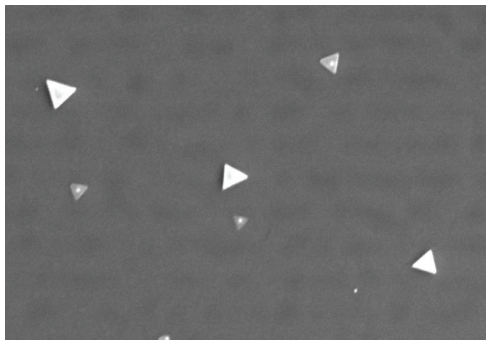
$1 \mu \mathrm{m}$

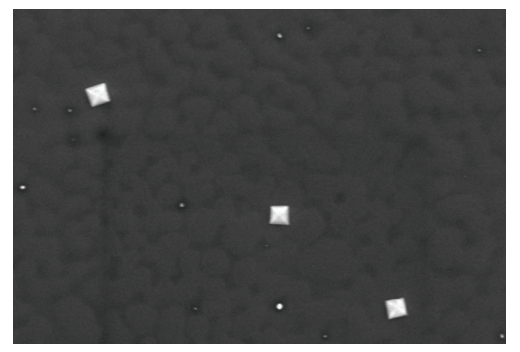

$\longrightarrow 1 \mu \mathrm{m}$

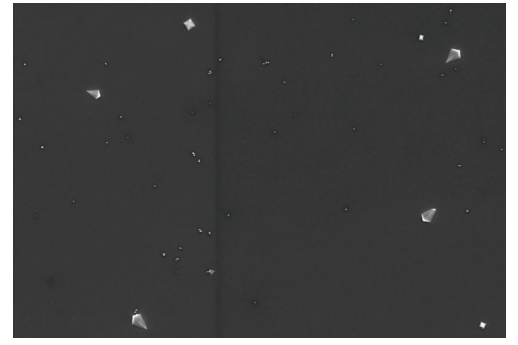

$-1 \mu \mathrm{m}$
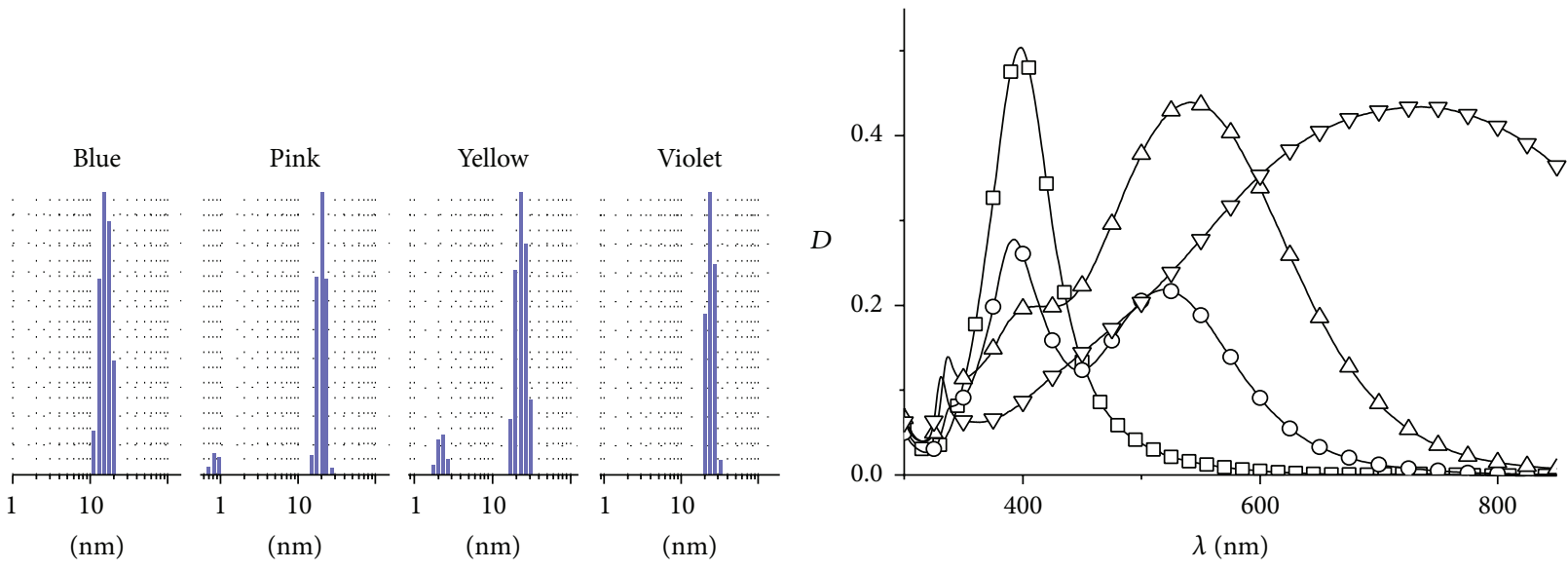

$$
\begin{array}{ll}
-\square \text { (1) Yellow } & - \text { (3) Violet } \\
-\circ \text { (2) Rose } & -\nabla \text { (4) Blue }
\end{array}
$$
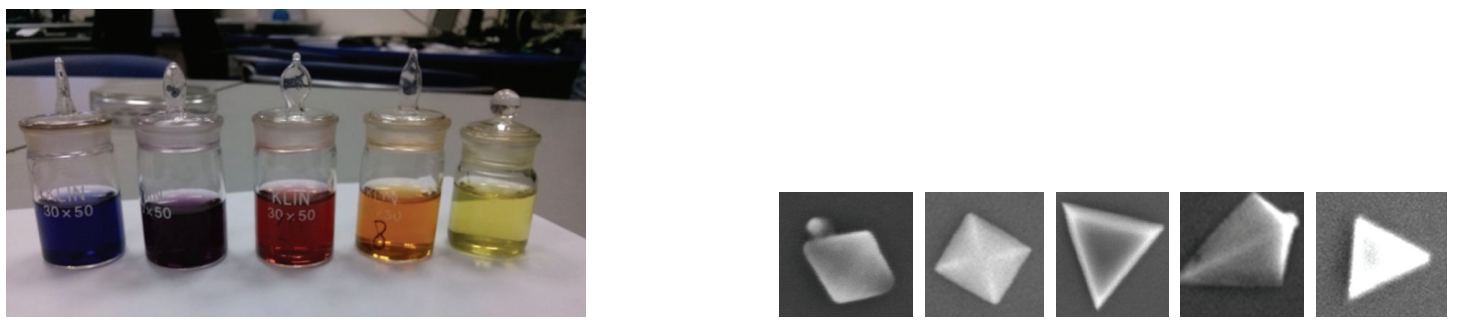

Figure 6: SEM images of Ag-NPs-3 on $n$-silicon, plasmon peaks, and size distributions from DLS data for the colloids of different colors.
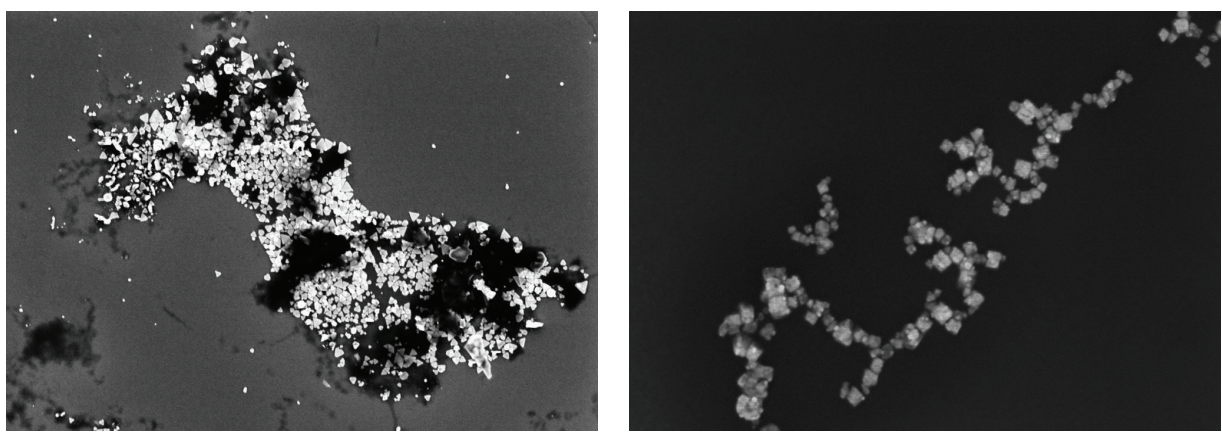

$1.5 \mu \mathrm{m}$

$1 \mu \mathrm{m}$

Figure 7: SEM images of DNA with Ag-NPs-3 of different shapes on a silicon substrate. The fixation was done from a solution of DNA with silver nanoparticles. 


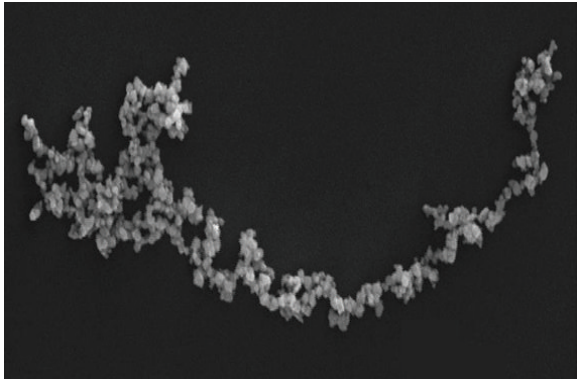

$1 \mu \mathrm{m}$

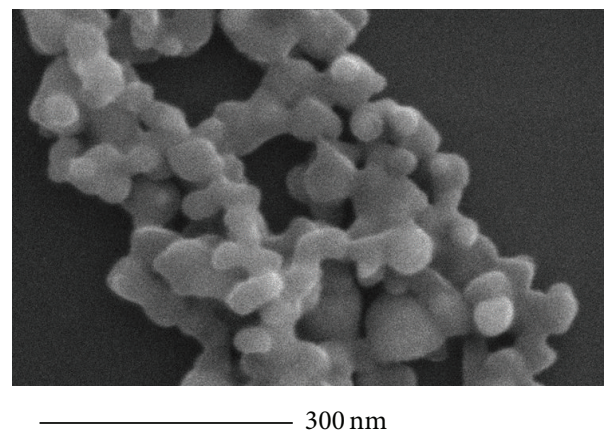

(b)

Figure 8: SEM (a) and SIM (b) images of Ag-NPs-1 attached to DNA fixed on $n$-silicon substrate.

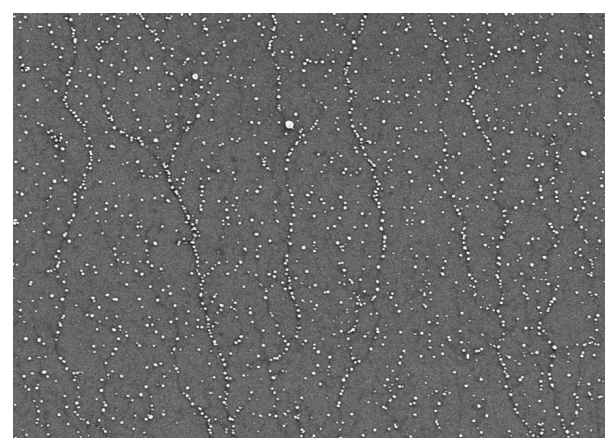

Figure 9: SEM image of DNA fibers with Ag-NPs-2 on $n$-silicon surface after the reduction of silver ions. DNA was fixed from the solution with $\mathrm{Ag}^{+}$ions before the reduction of silver.

It is known that the reduction of $\mathrm{Ag}^{+}$ions after their binding to DNA in a solution can produce two different silver nanostructures: nanoparticles with plasmon resonance and small fluorescent nanoclusters. The synthesis of Ag-NPs2 directly in the DNA solution produces the red shift and widening of the plasmonic band relative to that observed for the same system without DNA (Figure 13(a)). The plasmon peak in the DNA solution with $\mathrm{AgNO}_{3}$ and $5 \mathrm{mM} \mathrm{NaNO}_{3}$ was registered at $380 \mathrm{~nm} 1$ minute after the sequential addition of sodium borohydride (spectrum 2). This is a result of fast reduction of free $\mathrm{Ag}^{+}$ions in DNA solution and formation of Ag-NPs-2. In 75 minutes the increase in the intensity of the plasmon peak with its red shift was observed (spectrum 4). We suppose that a fast reduction of free silver ions in a solution is followed by slow formation of Ag-NPs on DNA strands. In this case the subtraction of spectrum 2 from spectrum 4 gives spectrum 5 for the fraction of NPs on DNA with plasmon peak at $396 \mathrm{~nm}$.

It is interesting to note that together with the synthesis of nanoparticles on DNA (Figure 13(a)), at low $\mathrm{Ag}^{+}$concentration in DNA solutions with the shortage of $\mathrm{Ag}^{+}$ions outside the helix, the reduction of silver ions causes the formation of the luminescent silver nanoclusters (Figure 13(b)). The small size of silver nanoclusters (up to 20 atoms) prevents the analysis of the systems with AFM technique [13]. At small concentrations of silver ions and the reductant in DNA solutions, the fluorescence of silver nanoclusters is observed. In this case almost all silver ions must be associated with DNA bases, and their reduction leads to the slow (in 1 day) formation of metallic nanoclusters within double helix in contrast to a relatively fast formation (about 1 hour) of silver NPs on DNA (Figure 13(a)). The adjacent nitrogen bases with potential binding sites for positive ions, usually guanines (N7G), determine the initial size of clusters with specific spectral band in Figure 13(b). We can suppose also that the reduction of silver ions destabilizes the DNA secondary structure, and hydrophobic bases form something like the stabilizing shell around each cluster. After the destruction of hydrogen bonds the additional sites for $\mathrm{Ag}^{+}$binding and cluster location (e.g., N3C and N1A) become available. The hydrophobic environment within double helix and the formation of a shell around clusters promote their stabilization from oxidation. Each NCs fraction has its own absorption and emission bands. It was shown that the excitation at $270 \mathrm{~nm}$ (within the DNA absorption band) causes the luminescence of all clusters [13]. Silver ions can form the coordination bonds with $\mathrm{N}$ atoms of nitrogen bases. This strong binding provides a stable linkage of silver to DNA. We propose that exactly these ions participate in NCs formation on dsDNA (and ssDNA).

Another result can be observed at the excess of $\mathrm{Ag}^{+}$ ions in DNA solution, when all the binding sites on the bases are filled, and the solution contains also many free silver ions or ions associated with phosphate groups outside the helix. In this case the formation of nanoparticles with the appearance of the plasmon peak is observed, and the fluorescence is completely absent. We never have seen quite reliable appearance of silver nanoclusters on DNA after the addition of Ag-NPs into DNA solution or after the formation of Ag-NPs-2 and Ag-NPs-3 in DNA solution. Thus, the equilibrium is shifted towards the formation of nanoparticles during the reduction of silver ions in DNA solution. It should be emphasized that for the formation of silver NPs (or silver nanoclusters) on DNA strands the preliminary binding of silver ions to DNA bases is necessary.

Accordingly, there are two alternative ways for DNA metallization in a solution via the reduction of silver ions: the formation of small fluorescent silver clusters within the helix 


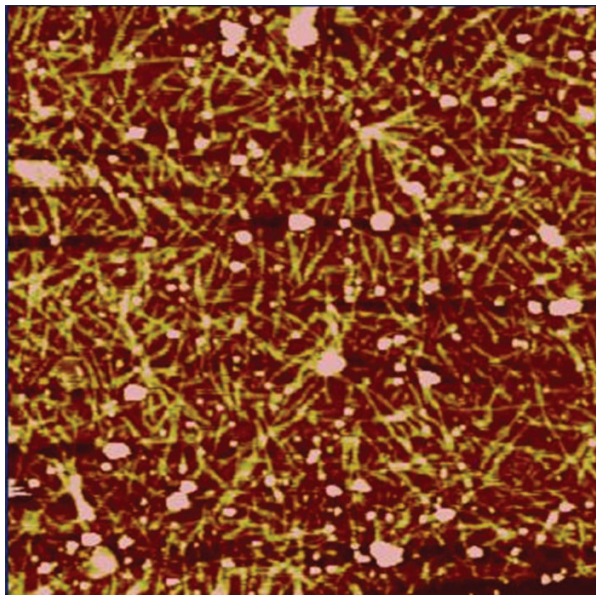

(a)

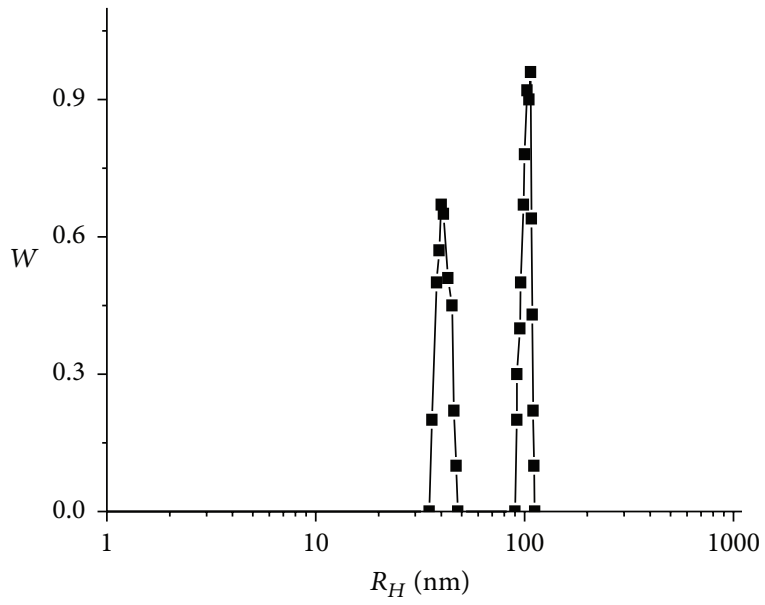

(c)

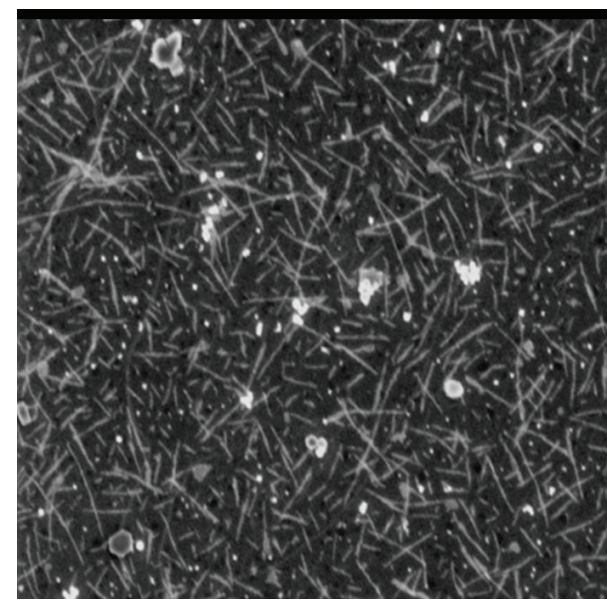

(b)

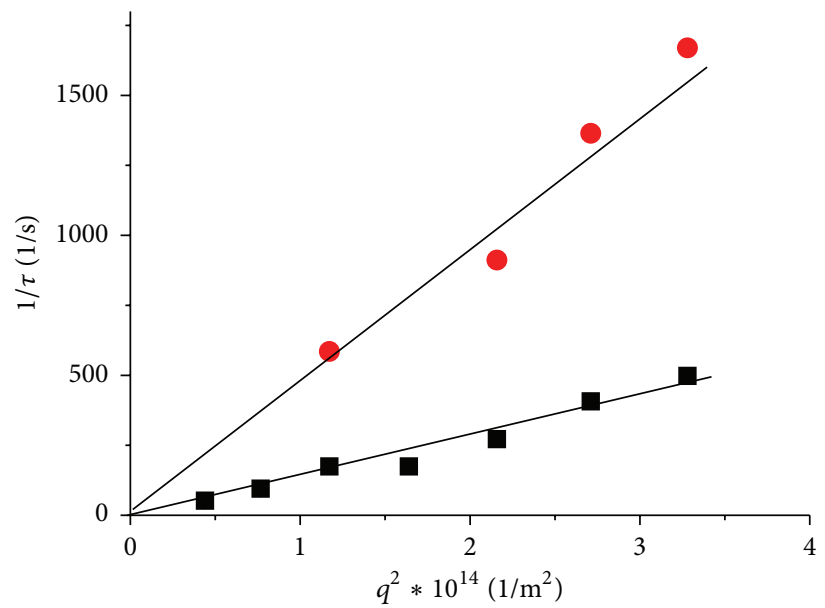

(d)

FIGURE 10: AFM (a) and SEM (b) images of Al-NPs on mica surface modified with APS (a) and on $n$-silicon substrate (b). The size distribution (c) and the angular dependences of $1 / \tau$ for two modes (d) and DLS experiment are also presented.

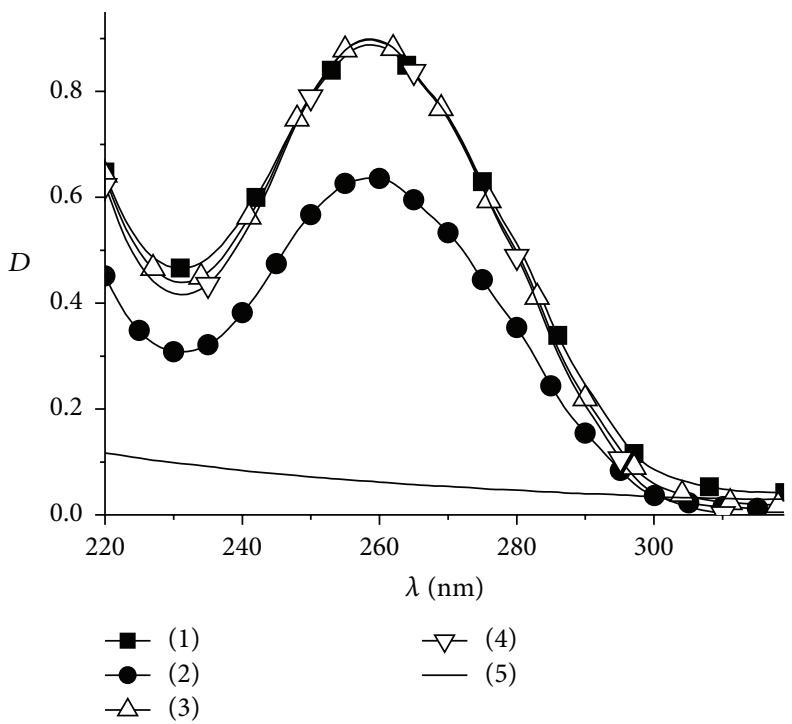

FIGURE 11: DNA absorption spectra in 5\% $(1,3)$ and $10 \%(2,4)$ solutions of Al-NPs (with subtracting the contribution of nanoparticles) after $(1,2)$ and before $(3,4)$ centrifugation, and optical density of solution with $10 \%$ Al-NPs $(5)$. All solutions contain $5 \mathrm{mM} \mathrm{NaCl}$. 


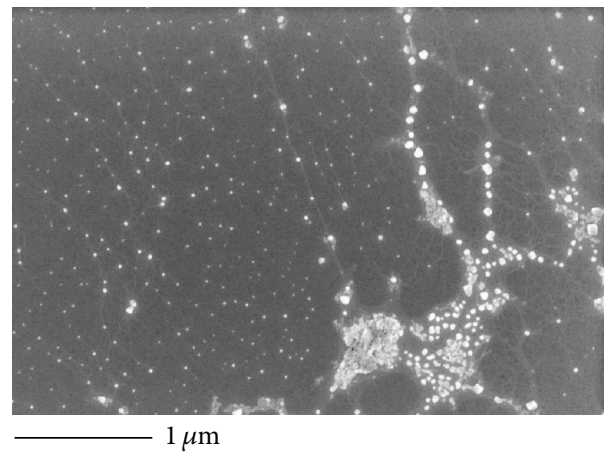

FIGURE 12: DNA with Al-NPs on $n$-silicon surface fixed from the bottom fraction of solution after the centrifugation.

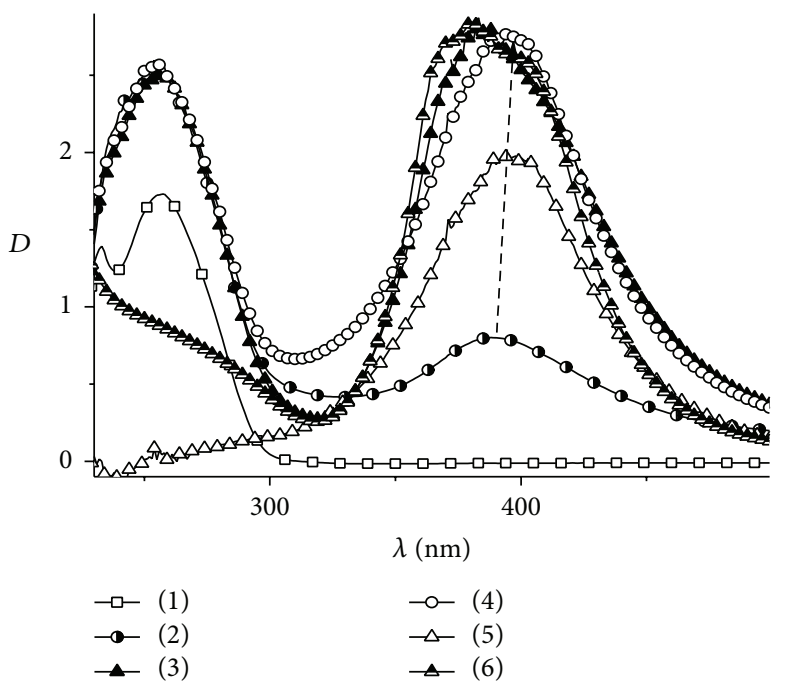

(a)

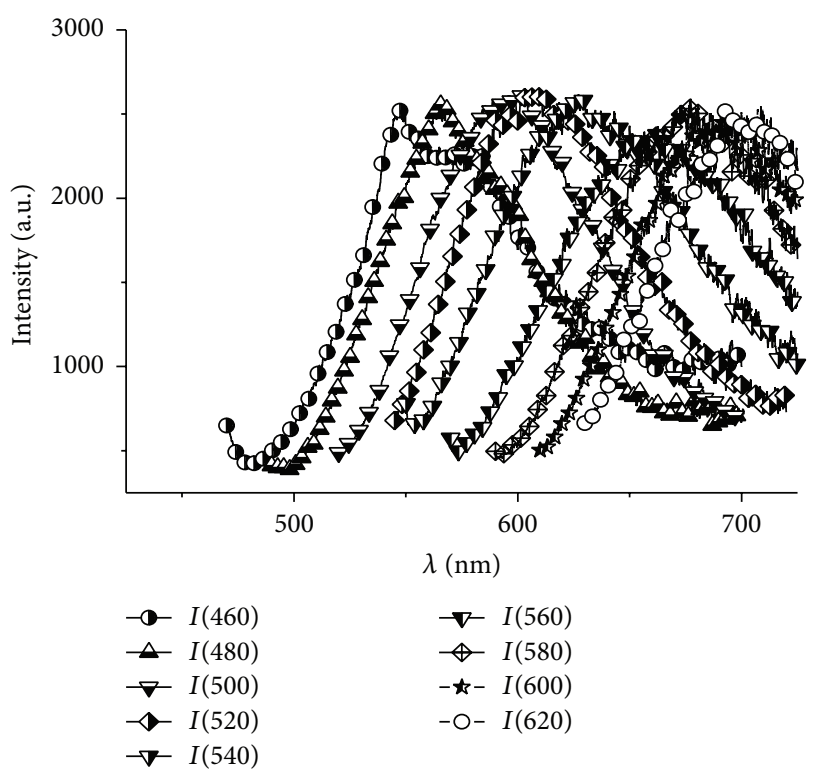

(b)

FIGURE 13: Absorption spectra (a) of DNA before (1) and after the reduction of silver (in 1 min (2) and 75 min (4)), DNA in solution with Ag-NPs-2 (3), calculated peak obtained by subtraction of spectrum 2 from spectrum 4 (5), and Ag-NPs-2 without DNA (6). The luminescence spectra (b) of silver nanoclusters on DNA (the excitation wavelengths are shown near the lines).

or the appearance of silver nanoparticles on DNA strands. Choice of the way is determined by $\mathrm{Ag}^{+}$, reductant, and DNA concentrations in a solution.

We examined DNA with Ag-NPs-2 and Ag-NPs-3 after the reduction of silver ions in DNA solution by AFM method (Figure 14). The images show the localization of Ag-NPs-2 directly on DNA chain (Figures 14(a) and 14(b)). When we use the metallization of DNA with the forming of triangle AgNPs-3 the result indicates that DNA prefers small spherical particles for the binding (Figures 14(c) and 14(d)).

CD spectra (Figure 15(a)) and the intrinsic viscosity (Figure 15(b)) of DNA after its metallization in a solution indicate the changes in the optical properties and in the volume of macromolecular coil. This result shows that nanoparticles localize on the DNA chain and influence the DNA structure. Indeed, DNA metallization causes the destabilization of the double helix. The decrease in the DNA intrinsic viscosity
[ $\eta$ ] (this value is determined as a result of extrapolation of the dependence of $\left(\eta_{r}-1\right) / C$ on $C$ in Figure $15(\mathrm{~b})$ to zero concentration of DNA) demonstrates the decrease in DNA persistent length. Indeed, the quality of solvent does not change. The reduction of silver on DNA breaks the hydrogen bonds between the bases and destroys stacking. The change in the volume of the molecular coil over time reflects the fall in the DNA rigidity. CD spectra of DNA in solutions with preprepared particles coincide with those for DNA in $5 \mathrm{mM}$ $\mathrm{NaNO}_{3}$. The addition of $\mathrm{Ag}^{+}$ions as well as their reduction in DNA solution causes changes in CD spectrum (Figure 15(a)).

\section{Conclusions}

It was shown that dsDNA does not interact with Ag-NPs-1 and Ag-NPs-2 in a solution. After the destabilization of its 


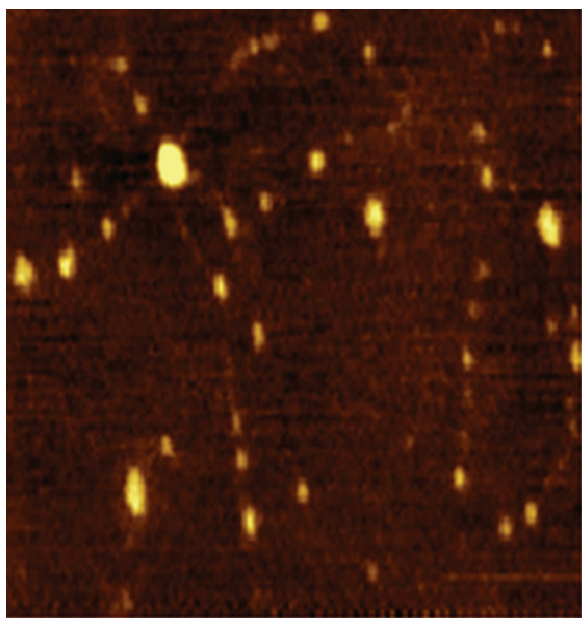

(a)

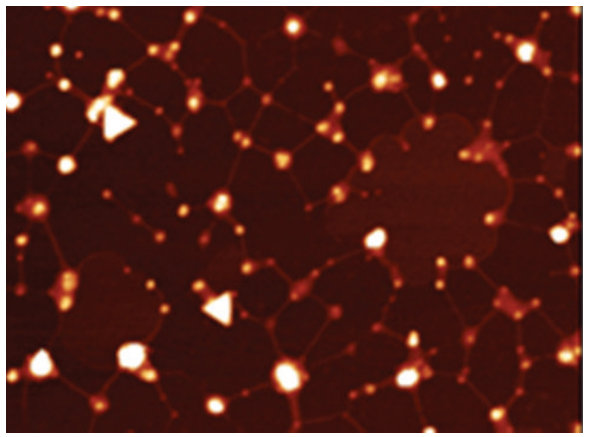

(c)
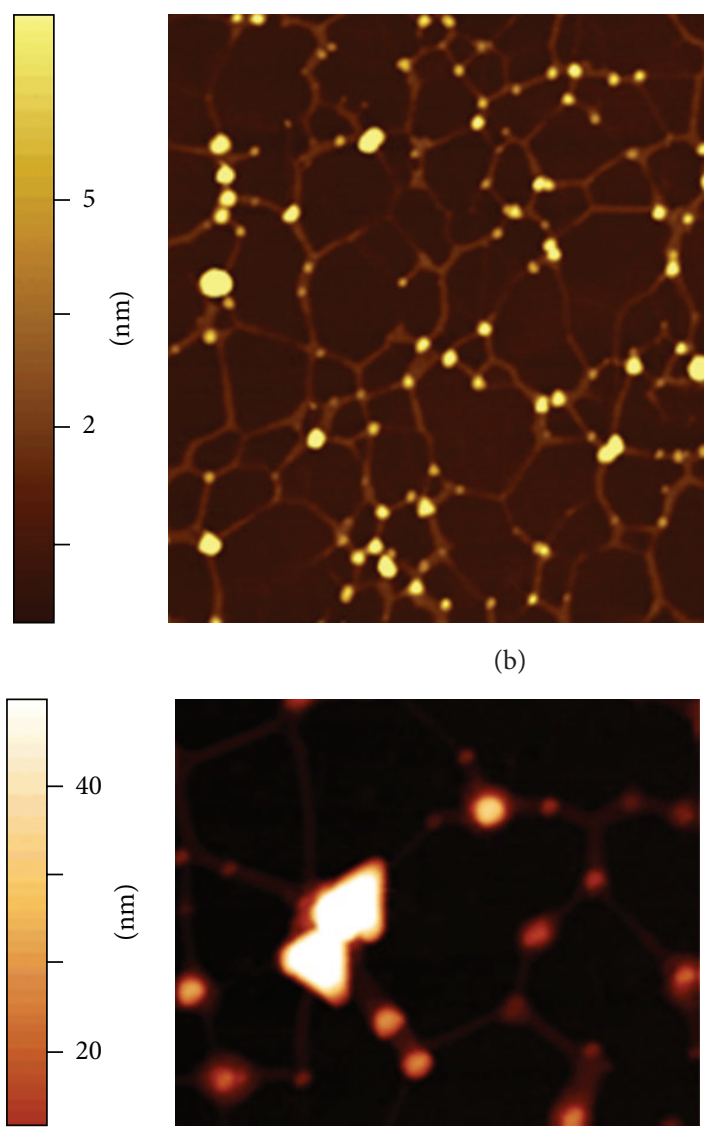

(d)

Figure 14: DNA with Ag-NPs-2 (a, b) and Ag-NPs-3 (c, d) after the reduction of $\mathrm{Ag}^{+}$ions in DNA solution. DNA fixation was carried out using $\mathrm{Mg}^{2+}$ ions. Ntegra Spectra instrument (direct scanning) was used.

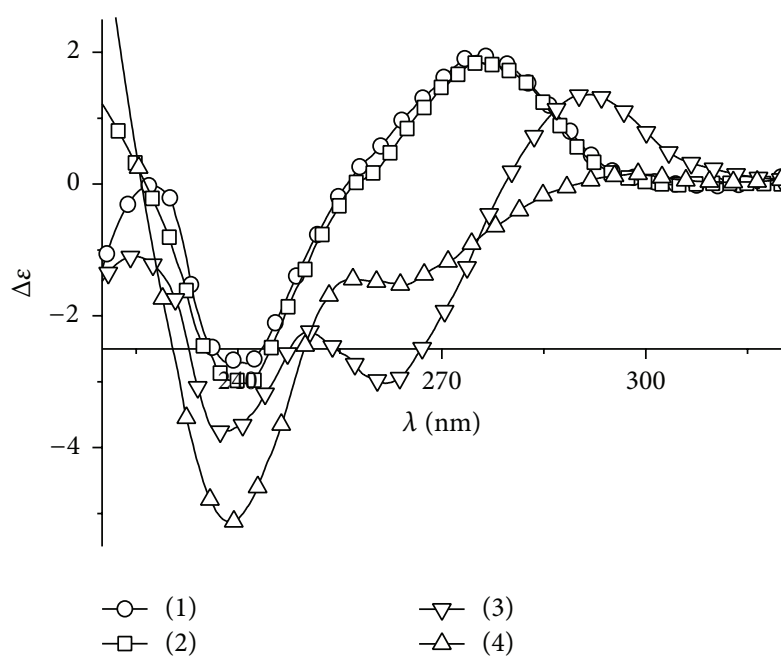

(a)

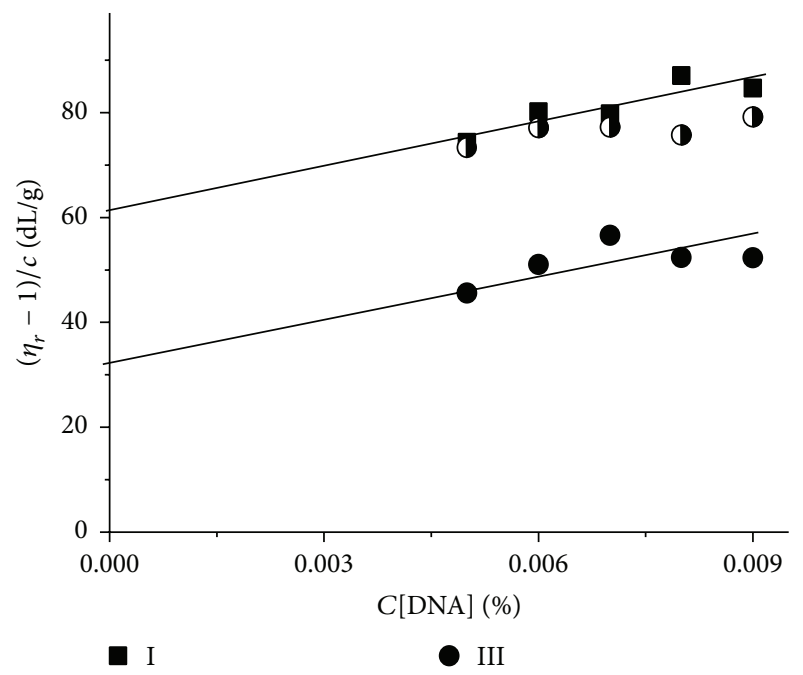

(b)

Figure 15: CD spectra (a) of DNA in $5 \mathrm{mM} \mathrm{NaNO}_{3}$ (1), with the addition of $\mathrm{NaBH}_{4}$ (2) and $\mathrm{AgNO}_{3}$ (3) and after the reduction of $\mathrm{Ag}^{+}$(4), $C(\mathrm{DNA})=2.4 \times 10^{-4} \mathrm{M}(\mathrm{P}), C\left(\mathrm{AgNO}_{3}\right)=6.7 \times 10^{-5} \mathrm{M}$, and $C\left(\mathrm{NaBH}_{4}\right)=5.6 \times 10^{-4} \mathrm{M}$. The dependence of the reduced viscosity of DNA solution $\left(\eta_{r}-1\right) / C$ on DNA concentration $C$ (b) without (I) and with Ag-NPs-2 (II, III) in 1 hour after the reduction (II) and in 2 days after the storage of solution II at $4^{\circ} \mathrm{C}$ (III). 
secondary structure the interaction can occur. DNA metallization on the $n$-silicon surface can produce systems with regular silver nanoparticles on DNA strands. The reduction of silver ions in a solution after their binding to DNA causes the fluorescence of silver nanoclusters when excited in the visible or ultraviolet region of the spectrum, or effect of plasmon resonance due to the formation of silver nanoparticles. We can observe free Ag-NPs and nanoparticles joined to the DNA strands. The sites of growth for NPs on DNA as well as the points of NCs localization can be determined by the initial location of $\mathrm{Ag}^{+}$ions. As it was mentioned above, the negative DNA phosphates and N7 guanine within the major groove are the possible positions for the binding of positive agents. Silver can coordinate to $\mathrm{N}$ atoms on DNA strands, whereas the oxygen of phosphates cannot participate in a stable complex with $\mathrm{Ag}^{+}$. The reduction of silver ions within the major groove of DNA destabilizes double helix. The alternative in the appearance of luminescent nanoclusters versus the fabrication of nanoparticles on DNA and outside the helix is the main intrigue of DNA metallization in a solution. In both cases silver ions on the bases in the major groove of DNA represent the initial points of silver nucleation for the formation of nanoclusters or nanoparticles. Only the absence of free $\mathrm{Ag}^{+}$ions in a solution can promote the formation of clusters inside the helix.

The selectivity is observed in DNA binding with Al-NPs. The small spherical particles can form regular sites of binding on DNA strands.

Our studies have shown that use of a variety of conditions for the reduction of silver in DNA solution allows us to get various ordered structures in solutions and on substrates with a given location of metallic silver under the form of nanoparticles or nanoclusters. Furthermore, it is possible to influence the optical properties of such systems.

\section{Conflict of Interests}

The authors declare that there is no conflict of interests regarding the publication of this paper.

\section{Acknowledgments}

This work was supported by RFBR (13-03-01192 a) and Saint Petersburg State University Foundation (11.38.644.2013).

\section{References}

[1] P. W. K. Rothemund, "Folding DNA to create nanoscale shapes and patterns," Nature, vol. 440, no. 7082, pp. 297-302, 2006.

[2] S. M. Douglas, H. Dietz, T. Liedl, B. Hogberg, F. Graf, and W. M. Shih, "Self-assembly of DNA into nanoscale three-dimensional shapes," Nature, vol. 459, pp. 414-418, 2009.

[3] W. P. Klein, C. N. Schmidt, B. Rapp et al., "Multiscaffold DNA origami nanoparticle waveguides," Nano Letters, vol. 13, no. 8, pp. 3850-3856, 2013.

[4] S. M. D. Watson, A. R. Pike, J. Pate, A. Houlton, and B. R. Horrocks, "DNA-templated nanowires: morphology and electrical conductivity," Nanoscale, vol. 6, no. 8, pp. 4027-4037, 2014.
[5] A. O. Puchkova, P. Sokolov, Y. V. Petrov, and N. A. Kasyanenko, "Metallization of DNA on silicon surface," Journal of Nanoparticle Research, vol. 13, no. 9, pp. 3633-3641, 2011.

[6] G. Doria, J. Conde, B. Veigas et al., "Noble metal nanoparticles for biosensing applications," Sensors, vol. 12, no. 2, pp. 1657-1687, 2012.

[7] K.-S. Lee and M. A. El-Sayed, "Gold and silver nanoparticles in sensing and imaging: sensitivity of plasmon response to size, shape, and metal composition," The Journal of Physical Chemistry B, vol. 110, no. 39, pp. 19220-19225, 2006.

[8] J. T. Petty, J. Zheng, N. V. Hud, and R. M. Dickson, "DNAtemplated Ag nanocluster formation," Journal of the American Chemical Society, vol. 126, no. 16, pp. 5207-5212, 2004.

[9] A. Latorre and Á. Somoza, "DNA-mediated silver nanoclusters: synthesis, properties and applications," ChemBioChem, vol. 13, no. 7, pp. 951-958, 2012.

[10] L. Shang, S. Dong, and G. U. Nienhaus, "Ultra-small fluorescent metal nanoclusters: synthesis and biological applications," Nano Today, vol. 6, no. 4, pp. 401-418, 2011.

[11] T. P. Bigioni, R. L. Whetten, and Ö. Dag, "Near-infrared luminescence from small gold nanocrystals," Journal of Physical Chemistry B, vol. 104, no. 30, pp. 6983-6986, 2000.

[12] L. A. Peyser, A. E. Vinson, A. P. Bartko, and R. M. Dickson, "Photoactivated fluorescence from individual silver nanoclusters," Science, vol. 291, no. 5501, pp. 103-106, 2001.

[13] I. L. Volkov, R. R. Ramazanov, E. V. Ubyivovk, V. I. Rolich, A. I. Kononov, and N. A. Kasyanenko, "Fluorescent silver nanoclusters in condensed DNA," ChemPhysChem, vol. 14, no. 15, pp. 3543-3550, 2013.

[14] C. A. Mirkin, R. L. Letsinger, R. C. Mucic, and J. J. Storhoff, "A DNA-based method for rationally assembling nanoparticles into macroscopic materials," Nature, vol. 382, no. 6592, pp. 607609, 1996.

[15] K. H. Lopatko, E. H. Aftandilyants, S. M. Kalenska, and O. L. Tonkha, "Mother colloidal solution of metals," B01J 13/00 Patent of Ukriane, vol. 38459, 2009.

[16] A. J. Frank, N. Cathcart, K. E. Maly, and V. Kitaev, "Synthesis of silver nanoprisms with variable size and investigation of their optical properties: a first-year undergraduate experiment exploring plasmonic nanoparticles," Journal of Chemical Education, vol. 87, no. 10, pp. 1098-1101, 2010.

[17] N. V. Bazlov, O. F. Vyvenko, P. A. Sokolov, N. A. Kas'Yanenko, and Y. V. Petrov, "Charge-controlled fixation of DNA molecules on silicon surface and electro-physical properties of Au-DNASi interface," Applied Surface Science, vol. 267, pp. 224-228, 2013.

[18] P. A. Sokolov, N. V. Bazlov, A. O. Puchkova, O. F. Vyvenko, and N. A. Kasyanenko, "DNA immobilization on n-type silicon surface and electrophysical properties of Au-DNA-(n-Si) structures," Protection of Metals and Physical Chemistry of Surfaces, vol. 47, no. 5, pp. 566-571, 2011.

[19] Y. L. Lyubchenko, L. S. Shlyakhtenko, and T. Ando, "Imaging of nucleic acids with atomic force microscopy," Methods, vol. 54, no. 2, pp. 274-283, 2011. 

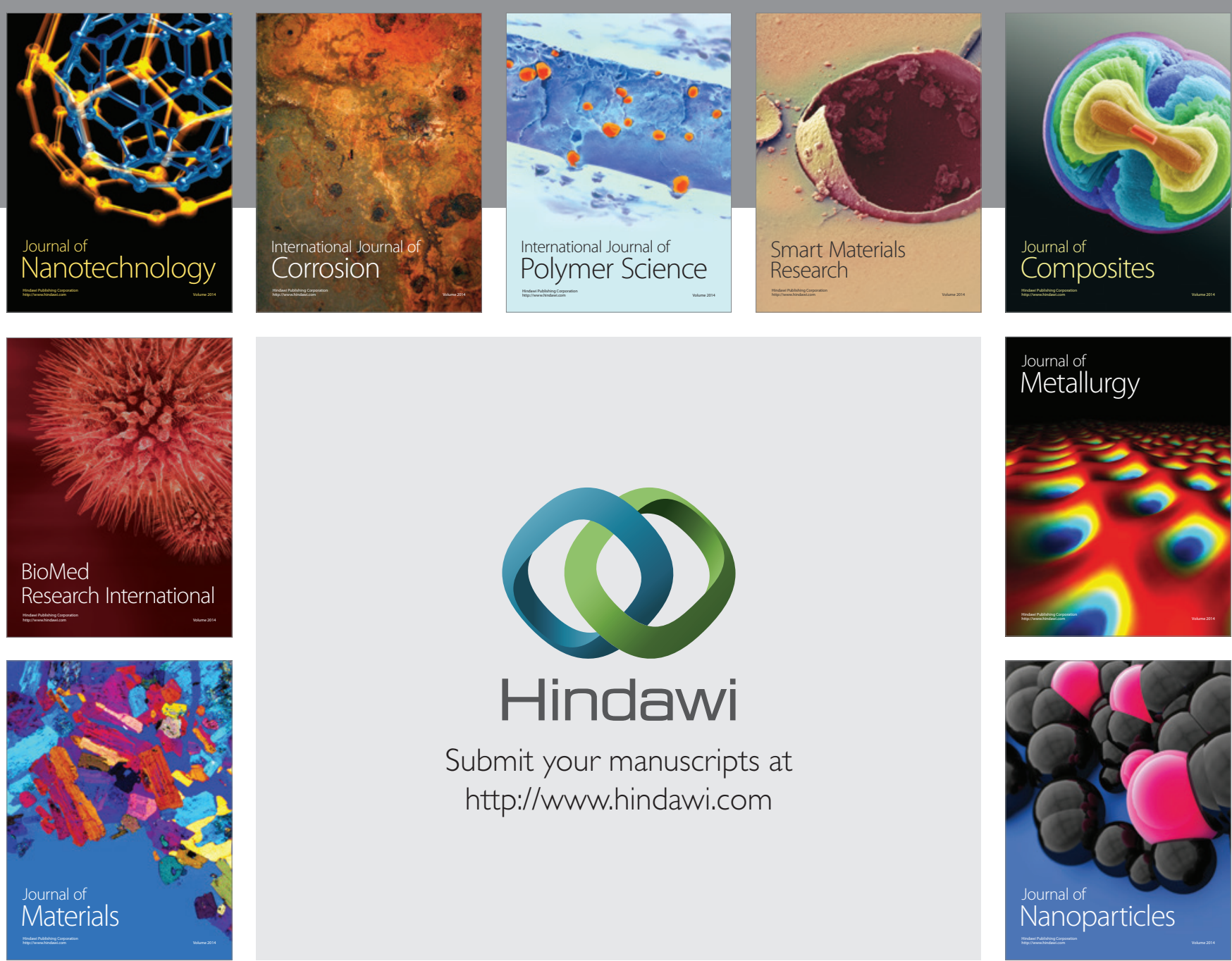

\section{Hindawi}

Submit your manuscripts at

http://www.hindawi.com

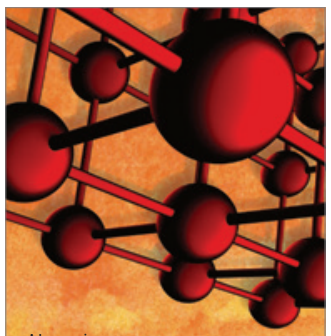

Materials Science and Engineering
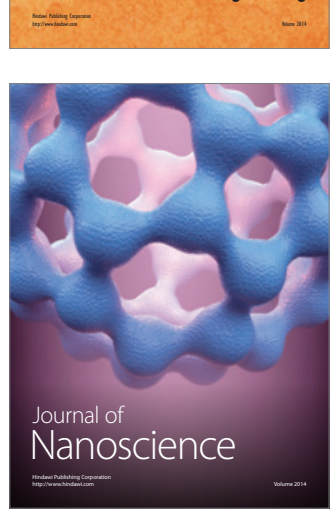
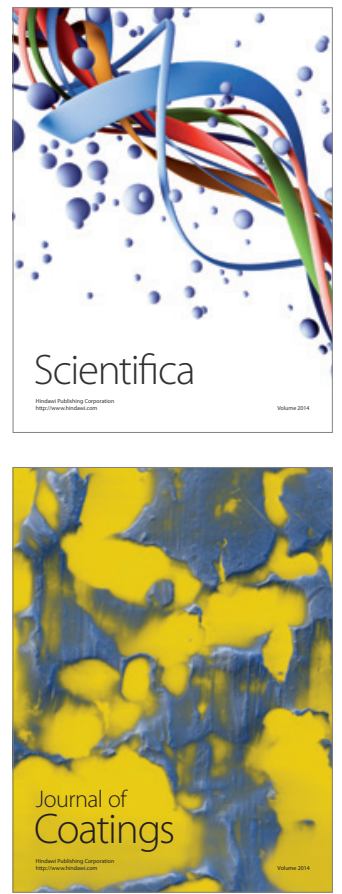
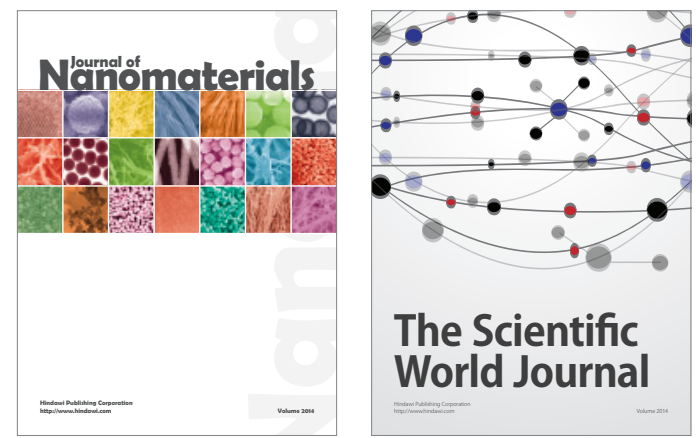

The Scientific World Journal
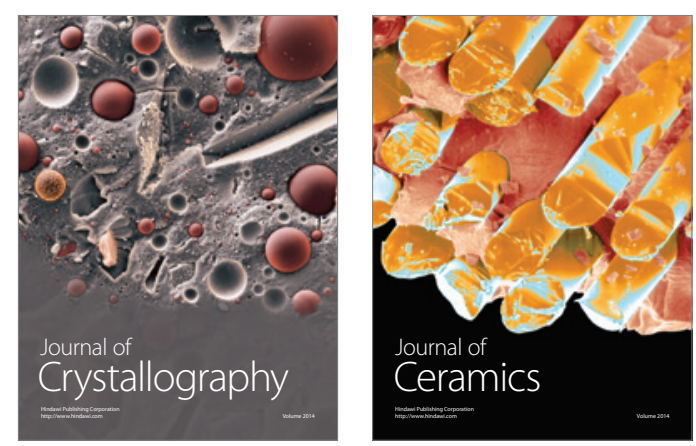
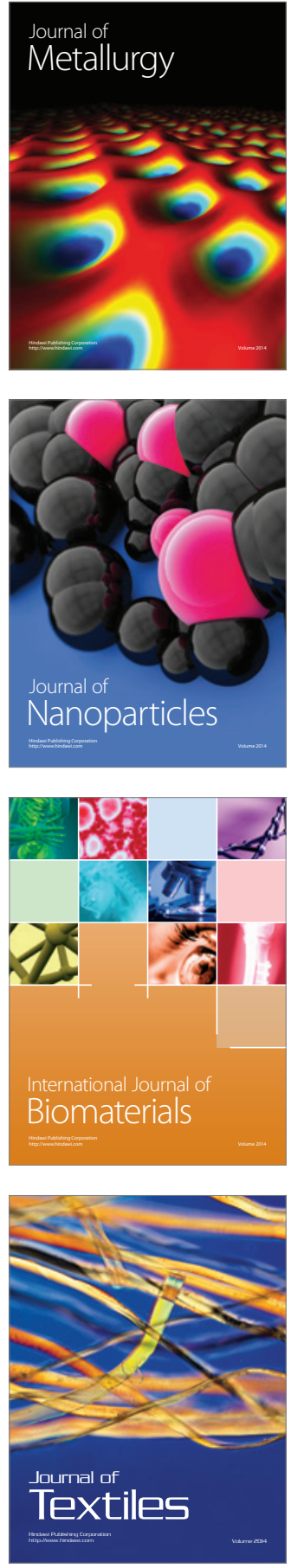